\title{
Alfabetismos aumentados: producir, expresarse y colaborar en la cultura digital
}

\author{
Mariana Ferrarelli \\ Universidad de San Andrés. \\ mferrarelli@udesa.edu.ar \\ ORCID: https://orcid.org/0000-0001-8549-0747 \\ Fecha de finalización: 30 de agosto de 2021 \\ Recibido: 3 de septiembre de 2021. \\ Aceptado: 16 de noviembre de 2021. \\ DOI: https://doi.org/10.26422/aucom.2021.1002.fer
}

\section{Resumen}

La crisis sanitaria global que alteró todos los ámbitos de la vida social renovó el debate sobre cuáles son las competencias y saberes necesarios para desempeñarse de manera efectiva en los escenarios atravesados por la digitalización y las plataformas mediáticas. Desarrollar la capacidad para buscar, seleccionar y reinterpretar información eficientemente, dominar el lenguaje audiovisual y los recursos digitales y tomar riesgos para resignificar viejos y nuevos aprendizajes emergen como habilidades vitales para aprovechar la coyuntura pospandémica. En el siguiente artículo repasamos las concepciones y contrastes más significativos sobre alfabetización tradicional, mediática y transmedia para enfocarnos en la categoría de alfabetismos aumentados, un término que proponemos para comprender la naturaleza y textura de las habilidades y saberes necesarios para interactuar, construir conocimiento y expresarse en los nuevos escenarios digitales y combinados. No se trata de abordar una enumeración de destrezas y desempeños, sino más bien de aproximarse a diversas competencias (mediáticas, expresivas, cívicas, lúdicas, narrativas, etc.) desde perspectivas más amplias que consideren el dinamismo y la complejidad del nuevo contexto. Se propone un recorrido bibliográfico divergente para posteriormente acceder a nuevas conceptualizaciones que delinean el campo teórico-práctico de una investigación en desarrollo.

Palabras clave: alfabetización digital, alfabetismo transmedia, alfabetismos aumentados, competencia mediática, cultura digital, escenarios híbridos.

\section{Augmented literacies: production, self-expression, and collaboration in digital culture}

\begin{abstract}
The global health crisis has affected every area of social life. And it renewed the debate on what competences and skills people need to thrive in environments where digitalization and digital media platforms are the norm. Among the key abilities required to take advantage of our post-pandemic moment, we can mention: knowing how to effectively search for, find, and reinterpret information; mastering audiovisual language and digital resources; and taking risks to
\end{abstract}


redefine old and new insights. In the following article, we review the most important concepts and contrasts regarding traditional, media, and transmedia literacy. We then focus on the category of augmented literacies, a term we propose to understand the nature and texture of the skills and know-how required to interact, build knowledge, and express oneself in our new digital and hybrid environments. We will not simply enumerate abilities. Rather, we will approach diverse skills (of the media, civic, expressive, ludic, or narrative variety, among others) from broad perspectives that consider the dynamism and complexity of our new context. We propose a divergent bibliography to reach new conceptualizations, which in turn can outline the theoretical-practical field of an ongoing investigation.

Keywords: digital literacy, transmedia literacy, augmented literacies, media competences, digital culture, hybrid environments.

\section{Alfabetismos aumentados: producir, expresarse y colaborar en la cultura digital}

\section{Resumo}

A crise sanitária global, que alterou todos os âmbitos da vida social, renovou o debate sobre quais são as competências e saberes necessários para desempenhar-se de maneira efetiva nos cenários atravessados pela digitalização e as plataformas midiáticas. Desenvolver a capacidade de pesquisar, selecionar e reinterpretar informações de forma eficiente, dominar a linguagem audiovisual e os recursos digitais e assumir riscos para ressignificar antigas e novas aprendizagens emergem como habilidades vitais para aproveitar a conjuntura pós-pandêmica. No seguinte artigo, repassamos as concepções e contrastes mais significativos sobre alfabetização tradicional, midiática e transmídia, para nos focalizar na categoria de alfabetismos aumentados, um termo que propomos para compreender a natureza e textura das habilidades, sensibilidades e saberes necessários para interagir, construir conhecimento e se expressar nos novos cenários tanto digitais como combinados. Não se trata de abordar uma enumeração de competências e desempenhos, mas sim de um modo de aproximação a diversas competências (mediáticas, expressivas, cívicas, lúdicas, narrativas, etc.) desde perspectivas mais amplas que considerem o dinamismo e complexidade do novo contexto. Propõe-se um percurso bibliográfico divergente para posteriormente ter acesso a novas conceituações que delineiam o campo teórico-prático de uma pesquisa em desenvolvimento.

Palavras-chave: alfabetização digital, alfabetismo transmídia, alfabetismos aumentados, competência mediática, cultura digital, cenários híbridos.

\section{Introducción}

La pandemia aceleró las mutaciones en el modo en el que tradicionalmente se construye el conocimiento y en el que los sujetos se desempeñan en contextos laborales, educativos y sociales en general. Los escenarios se complejizan; para atravesarlos de manera efectiva es preciso desarrollar habilidades y sensibilidades que comprometan viejos aprendizajes, los resignifiquen y los prolonguen.

No es sencillo entrar y salir de la intermitencia y del vértigo del formato online/ offline que proponen las reuniones de trabajo, conversaciones familiares y clases en todos los niveles del sistema educativo. Es necesario procesar la información, los vín- 


\section{Austral @municación \\ Volumen 10, número 2 (Diciembre de 2021): 395-411 ISSN (I) 2313-9129. ISSN (E) 2313-9137}

culos y los recursos comunicativos materiales y simbólicos de manera abierta, flexible y contextualizada.

Pensar la alfabetización digital en términos de alfabetismos aumentados busca poner en tensión el modo en el que pensamos la alfabetización: implica ya no un compendio de habilidades y saberes, sino de competencias y marcos de acción que se acumulan en capas, enriquecen gradualmente la percepción del contexto y los desempeños y despliegan un proceso en permanente movimiento y resignificación al que se le otorga un sentido y una dirección. El presente artículo da cuenta de los primeros pasos de una investigación que pretende indagar y sistematizar distintas disposiciones y conocimientos que se activan en contextos que combinan no solo el aprendizaje informal, sino también el que ocurre en contextos formales, y explorar los cruces entre disciplinas varias y campos profesionales, tiempos y espacios dentro y fuera del aula e instancias online/offline. Ofrecemos a continuación una breve sistematización bibliográfica que forma parte y sienta las bases teóricas de una investigación en curso, cuyo objeto de estudio lo constituyen las prácticas de diseño de propuestas didácticas llevadas adelante por docentes de nivel superior en diferentes contextos institucionales $\mathrm{y}$ tecnológicos.

\section{Tecnología y educación}

Para comprender los alcances del avance tecnológico en todas las esferas de la socialidad, pero en particular en el campo educativo y laboral-profesional, basta mirar un aula y observar cómo a las tecnologías analógicas tradicionales del lápiz y el papel, y la máquina de escribir, se les suman los dispositivos y medios digitales que ingresan a la escuela y a la universidad por la porosidad de sus paredes, ahora virtualizadas. En un mundo en el que cualquier intercambio social, comercial y simbólico ocurre en el espacio de alguna plataforma mediática, es necesario conocer el potencial de las tecnologías digitales y operarlas no solamente de manera instrumental, sino también en términos socioculturales, discursivos y reflexivos: esto implica comprender que, más allá de las cuestiones técnicas, las herramientas y dispositivos proponen modos de socialidad y de construcción del conocimiento que hunden sus raíces en saberes y haceres cultural e históricamente situados.

Hasta hace un siglo, una persona analfabeta era aquella que, por ejemplo, no conocía los principios mínimos de la escritura y el cálculo, mientras que se consideraba culto a quien tenía la capacidad no solo de escribir y hacer matemática, sino también de acceder a libros y revistas y poseer el capital cultural (Bourdieu, 2005) necesario para interpretarlos y comprender los significados expresados por el autor. En la actualidad, el concepto de "alfabetización" es mucho más amplio porque incluye las habilidades mínimas que un sujeto debe poner en funcionamiento para interactuar de manera 
Mariana Ferrarelli

Alfabetismos aumentados: producir, expresarse y colaborar en la cultura digital

efectiva y eficiente en el entorno social hipertecnologizado y mediado por alguna plataforma digital. En palabras de Area Moreira (2012):

Un sujeto culto -es decir, alfabetizado en las nuevas formas culturales-, además de leer y escribir textos impresos debe ser capaz también de interactuar con un sistema de menús u opciones mediante un teclado, un ratón o una pantalla táctil, saber navegar a través de documentos hipertextuales sin perderse, conocer los mecanismos y procedimientos para grabar imágenes, procesarlas y difundirlas en un sitio web, poseer las destrezas para buscar y encontrar en la Red aquel dato o información que necesita para resolver un problema, saber discriminar y otorgar significado a las numerosas informaciones que llegan diariamente por múltiples medios, escribir un documento y enviarlo por correo electrónico, participar en un foro expresando su opinión y, en fin, subir fotos, videos o presentaciones para compartirlos con otras personas en una red social, etc. (p. 5)

La alfabetización supone conocer las formas culturales de una época y un lugar y apropiarse de ellas para participar en diversos intercambios tanto sociales como culturales, laborales y económicos. A partir de la pandemia global, estas formas culturales se ven expandidas, modificadas y multiplicadas y buscan adaptarse a los desarrollos tecnológicos y a las transformaciones ocurridas en el ecosistema mediático.

Entendemos los alfabetismos aumentados no solo como un conjunto de destrezas que ya han sido enumeradas en estudios anteriores (Area Moreira, 2012; Ferrarelli, 2017; Ferrés y Piscitelli, 2012; Gutiérrez Martín, 2003; Instituto Iberoamericano de TIC y Educación, s.f.; Instituto Nacional de Tecnologías Educativas y Formación del Profesorado, 2017; International Society for Technology in Education, 2017; Lara, 2009; Pedró, 2011; Scolari, 2018; UNESCO, 2011), sino también como una perspectiva para abordar esas mismas competencias de manera combinada, flexible y en cambio permanente. La propuesta es pensar las habilidades como capas o niveles que se superponen para enriquecer las prácticas y el posicionamiento desde el cual los usuarios producen saberes y materiales en entornos digitales. Sostenemos un enfoque que busca abordar las prácticas digitales desde su materialidad como objetos en movimiento y procesos en constante evaluación y construcción. En palabras de Trejo Delarbre (2021), lo digital subyace a todas las prácticas y es parte de la subjetividad y la vida cotidiana de las personas:

Fascinante e inevitable, el entorno digital nos envuelve, está en nuestras vidas y de varias maneras formamos parte de él. Consumimos, propagamos y hacemos cultura digital todos los días, todo el tiempo. Pero no necesariamente la comprendemos ni somos capaces de identificar la densidad y la evolución de lo digital en cada segmento del mundo contemporáneo. (p. 7)

Desde el punto de vista metodológico, la propuesta de pensar los alfabetismos aumentados busca indagar en las competencias y miradas puestas en juego por los sujetos para identificar la densidad y evolución de lo digital en diferentes contextos educativos 


\section{Austral @municación \\ Volumen 10, número 2 (Diciembre de 2021): 395-411 ISSN (I) 2313-9129. ISSN (E) 2313-9137}

y profesionales. Para ello, se avanzó en un proceso de revisión bibliográfica sistemática (Codina, 2018a, 2018b) a partir del cual se analizaron y relevaron diversas fuentes científicas relacionadas con la integración de tecnologías en la enseñanza, modelos de alfabetización y competencia digital en el profesorado y su vínculo con la subjetividad docente. Además de las fuentes bibliográficas tradicionales y textos especialmente seleccionados, se adoptó el marco SALSA (Grant y Booth, 2009, como se citó en Codina, 2018b), que organiza el trabajo en cuatro etapas sucesivas: búsqueda, evaluación, análisis y síntesis. La exploración y selección de textos que conforman la sistematización bibliográfica se realizó a partir de los siguientes sitios que funcionaron como base de datos: AcademiaEdu, ResearchGate y Google Scholar. Para los modelos de competencia digital docente, se optó por consultas las bases de datos oficiales de los organismos involucrados: UNESCO, Instituto Iberoamericano de TIC y Educación (IBERTIC) e Instituto Nacional de Tecnologías Educativas y Formación del Profesorado (INTEF).

Las preguntas de investigación se derivan del siguiente interrogante general que enmarca el trabajo de indagación: si cambian las formas de conocer, de relacionarnos con los dispositivos y de vincularnos con otras personas, ¿por qué no pensar que también se modifica la relación entre viejos y nuevos aprendizajes, a la vez que cambian las habilidades necesarias para construir saberes y distribuirlos en la complejidad del contexto pandémico? El concepto de "alfabetismos aumentados" (aún en construcción) busca entrelazar el desarrollo de diversas competencias (mediáticas, lúdicas, digitales, narrativas, etc.) con la complejización de los nuevos escenarios a partir de la crisis sanitaria (Ferrarelli, 2020) y la aceleración de las transformaciones que ya predominaban en el ecosistema mediático. La investigación no busca producir u ofrecer como resultado la conformación de una nueva matriz de habilidades mediáticas o digitales. El objetivo es proponer más bien un modo convergente y trenzado de estructurar saberes $\mathrm{y}$ formatos adquiridos en diferentes contextos, que se adaptan y recombinan para atravesar los nuevos entornos y avanzar en el diseño de propuestas de trabajo adaptadas a los escenarios que propone el nuevo contexto. Por ejemplo, para planificar una clase o un seminario de formación profesional antes de la pandemia bastaba con seleccionar un contenido y un formato de trabajo y organizar algunas actividades de intercambio entre los participantes. En general, la presencialidad física aseguraba la copresencia y la simultaneidad para el trabajo conjunto. En la actual coyuntura, los tiempos y espacios diversificados requieren no solo otro enfoque para la implementación, sino también para la planificación de cualquier actividad formativa, sea educativa o no.

Conocer las características propias de los diferentes entornos y las posibilidades del contexto son solo algunas de las habilidades que es necesario tener en cuenta para llevar adelante diversas iniciativas y actividades en los escenarios híbridos. Del trabajo de campo en curso también surgen otras competencias imprescindibles para desem- 
Mariana Ferrarelli

Alfabetismos aumentados: producir, expresarse y colaborar en la cultura digital

peñarse en la nueva coyuntura para producir materiales y circularlos, colaborar empática y solidariamente con otros y compartir ideas y reflexiones en redes sobre temas de interés o movimientos sociales. Se trata de habilidades y sensibilidades o modos de abordar los vínculos, tales como tomar riesgos para aprender algo nuevo, aceptar exponerse frente a pares y/o colegas, confiar en otros usuarios para lograr un objetivo y construir saberes y procedimientos colaborativamente, entre otros. A partir de estas primeras exploraciones, podemos afirmar que las prácticas y saberes acumulados se recombinan en nuevas tramas que se expanden y transforman mutuamente para adaptarse al nuevo contexto.

\section{La conversión digital como modo de alfabetización}

El campo de estudio sobre alfabetización mediática ha reunido tradicionalmente a especialistas y enfoques provenientes del campo de la educación y la comunicación. La preocupación por los efectos de los medios en los jóvenes se remonta a la década del 60 , cuando expertos en educación y comunicación comenzaron a proponer estrategias para evitar el efecto nocivo sobre todo de la televisión en las nuevas generaciones. Esta primera corriente concentrada en la media literacy (alfabetización en medios) fue sucedida más recientemente por la preocupación sobre el manejo de los nuevos medios digitales, incluyendo videojuegos y redes sociales para convertirse en new media litera$c y$. Al foco en el impacto de la televisión y la radio en las conciencias de niños y jóvenes le siguió la problematización de los medios digitales, de allí que la new media literacy también se denomine "alfabetización digital" (Area Moreira, 2012; Gutiérrez Martín, 2003; Lara, 2009; Pedró, 2011; Ribeiro Pessoa et al., 2015).

De acuerdo con Area Moreira (2012), los desarrollos sobre alfabetización digital surgen a partir de dos tendencias emergentes que se dan en un mundo y un mercado cada vez más atravesados por entornos digitales. Por un lado, existe el interés por que los consumidores desarrollen las competencias necesarias para interactuar y comprar a través de la web: la economía global necesita trabajadores competentes que posean las destrezas requeridas para ingresar al mercado laboral y de consumo. La alfabetización digital adquiere características instrumentales y pone el énfasis en el entrenamiento en el manejo de dispositivos y herramientas. Por otro lado, en paralelo a esta concepción más de tipo mercantilista, surge la preocupación por formar ciudadanos responsables y críticos en el uso de la tecnología. El ejercicio de la ciudadanía aparece estrechamente relacionado con la capacidad de convertir la información en conocimiento y utilizarlo para tomar decisiones dentro de marcos intelectuales y éticos compartidos con otros. A la formación instrumental de los sujetos se le suma el desarrollo de capacidades críticas para configurar una identidad responsable y coherente dentro del mundo digital. 


\section{Austral @municación \\ Volumen 10, número 2 (Diciembre de 2021): 395-411 ISSN (I) 2313-9129. ISSN (E) 2313-9137}

Por su parte, la web 2.0 también plantea desafíos, dado que, a diferencia de su versión anterior -la web 1.0-, les permite a los usuarios la producción y circulación de sus propios contenidos a través de diversos medios. A diferencia de las páginas web tradicionales que solo les permitían a los usuarios la lectura y la navegación hipertextual, en la actualidad, la web 2.0 se convierte en escenario de expresión personal y colectiva utilizando diversos lenguajes y tecnologías interactivas. En términos educativos, la web 1.0 era más parecida al modelo de clase expositiva, heredero de los medios de tipo broadcast, como la radio, la prensa escrita y la televisión. Por su parte, la web 2.0 habilita desde su conformación y estructura técnica intercambios más personalizados del tipo uno-a-uno, que convierten a cada usuario en nodo dentro de una red de interacciones; éste último aspecto cambia el esquema de jerarquías y roles tanto en el mundo digital como en el físico.

A estas transformaciones es preciso agregarles los efectos de la convergencia de medios y lenguajes que facilitan las tecnologías digitales. Las prácticas que antes ocurrían por separado, en la actualidad se desarrollan en un mismo entorno, el digital, y mediante un solo dispositivo: generalmente un celular inteligente. A lo largo de un extenso y profundo ensayo sobre la cultura de la convergencia, Milad Doueihi (2010) analiza las transformaciones que ocurren en la cultura y en el imaginario social a través de lo que él denomina "conversión digital". Según el autor, hasta hace aproximadamente dos décadas la cultura digital conservaba una importante impronta proveniente de la cultura impresa y de sus formatos más conocidos (página, párrafo, libro, copyright, autoría individual, etc.). Sin embargo, el proceso de conversión digital al que hace referencia se relaciona con prácticas emergentes que se desvinculan del mundo impreso y avanzan hacia un marco de nuevos conceptos y prácticas autónomas. Lo digital en este sentido no se relaciona exclusivamente con un entorno y unas herramientas, sino también con una nueva cosmovisión que impacta directamente sobre las concepciones sociales, políticas y culturales de los sujetos, por eso su carácter civilizatorio. Señala Doueihi (2010): "La alfabetización digital vehicula un imaginario social que pone en juego no solo la dimensión virtual de las nuevas tecnologías sino también determinados postulados y prejuicios religiosos, históricos y políticos” (p. 15). Para el autor, lo digital adquiere las características de un proceso civilizador con sus dinámicas y mutaciones específicas, que es preciso analizar en detalle. Tal como veremos más adelante, cuando conceptualicemos la naturaleza de los alfabetismos aumentados, al estudio de las características y competencias técnicas debe sucederle el análisis cultural del entorno tecnológico, que va más allá de cuestiones operativas y se marca en prácticas socioculturales situadas y complejas. Por sus atributos universalistas y su alcance político y social, Doueihi (2010) le otorga a la conversión digital las características 
Mariana Ferrarelli

Alfabetismos aumentados: producir, expresarse y colaborar en la cultura digital

propias de una cosmovisión integral en tanto su función narrativa permite explicar el presente y el futuro de la sociedad.

En su análisis, Doueihi (2010) establece contrapuntos interesantes entre la cultura impresa y la digital. La primera, relativamente fija y con un orden espacio-temporal lineal, se opone al dinamismo de lo digital, que es maleable, flexible y adaptable a diversos formatos. La figura estable del autor-productor que define contenidos y se apoya en la autoridad del canon letrado se enfrenta con prácticas culturales de producción de contenidos en manos de lectores-prosumidores. A modo de cazador cazado, el texto impreso, que en su momento promovió una revolución social al extender socialmente las prácticas de lectura y escritura y derribar la autoridad de las élites letradas, se ve hoy amenazado por las múltiples fracturas digitales que producen las tecnologías. El concepto de "alfabetización digital" que promueve Doueihi (2010) en tiempos de convergencia "está lejos de limitarse a la mera manipulación de las herramientas disponibles, al feliz empleo de las múltiples posibilidades que se ofrecen a los usuarios hoy. Al igual que la alfabetización de la cultura impresa es densa y compleja" (p. 35). A la par de la cultura digital se genera un nuevo entramado de relaciones políticas, económicas y sociales que es preciso desmenuzar en detalle: de aquí que resulte tan necesario desarrollar capacidades específicas para comprender las prácticas a las que da lugar. Al igual que el contexto en el que surgen, estas prácticas son siempre parciales y móviles; no se agotan en saberes establecidos y fijos, sino que se trata más bien de habilidades poliédricas y en construcción permanente, un atributo clave de los alfabetismos aumentados.

\section{La cultura participativa como marco para la acción}

Los marcos teóricos que se ocupan de conceptualizar las competencias necesarias para desempeñarse adecuadamente en el entorno digital no pierden de vista el rol de adultos y maestros como acompañantes y guías en el desarrollo de niñas, niños y jóvenes en entornos tecnológicos. Al respecto, Dussel y Quevedo (2010) indican que

la mediación del mundo adulto sigue siendo fundamental y quizás más todavía en esta
cultura dominada por la proliferación de signos, al tiempo que señalan la centralidad de
la institución escolar para ayudar a dar forma, lenguaje y contenido a nuevas esperanzas
y deseos, y también a apropiarse de manera más relevante de todas esas enormes posibili-
dades que hoy prometen las nuevas tecnologías. (2010, p. 74)

El término "cultura participativa" proviene del corpus teórico elaborado por Henry Jenkins (2006) en su análisis de la cultura digital. Se trata de los formatos más transversales y horizontales de participación y creación cultural que favorecen los nuevos medios, en especial las redes sociales y las plataformas de blogging y microblogging que permite la web 2.0. Pensamos que en contextos escolares y extraescolares la cultura 


\section{Austral Omunicación \\ Volumen 10, número 2 (Diciembre de 2021): 395-411 ISSN (I) 2313-9129. ISSN (E) 2313-9137}

participativa fomenta el aprendizaje entre pares, promueve la diversidad de formas de expresión y les permite a los ciudadanos acceder a modos efectivos de comunicación. Henry Jenkins et al. (2016) desarrollan la idea de aprendizaje conectado que emerge de la línea de investigaciones en medios digitales y aprendizaje en la Fundación MacArthur. De acuerdo con Mimi Ito (2016), la tecnología digital posee el potencial para continuar reproduciendo modelos tradicionales de enseñanza y aprendizaje. Un buen ejemplo de ello lo constituyen los programas que les permiten a los estudiantes realizar ejercicios por repetición y hacer más eficientes los sistemas de evaluación sumativa. Las transformaciones entonces no provienen de las herramientas y dispositivos en sí mismos, sino del enfoque a partir de los cuales se generan sentidos para su integración.

En este sentido, Ito (2016) también observa que las tecnologías les posibilitan a los jóvenes conectarse entre sí mediante un interés compartido y les permiten:

\footnotetext{
obtener conocimiento y habilidades en la interacción con pares en torno a propósitos y pasiones compartidas a la vez que utilizan herramientas digitales para nuevas formas de producción creativa [...]. En estos contextos el aprendizaje es un efecto colateral de la producción creativa, la colaboración y la organización comunitaria, no el propósito explícito de la actividad. $Y$ es probable que esos mismos jóvenes hubieran aprendido tanto en un contexto de educación formal en busca de una buena calificación. (p. 92)
}

Ito (2016) reconoce que quienes participan en estas comunidades son una minoría de jóvenes. De todos modos, desde el campo de la educación señala la relevancia de padres, educadores y adultos en general para fomentar estos intereses y conectar este tipo de prácticas con posibilidades académicas, laborales y de participación ciudadana.

Henry Jenkins (2016), por su parte, destaca la relevancia del aprendizaje participativo que pone el foco en respetar las contribuciones de cada participante sin importar si se trata de un docente, estudiante o actor extraescolar. En este contexto, la alfabetización es definida ya no tanto como la habilidad para producir y consumir información, sino como la capacidad para participar en un sistema social más general en el cual los actores comparten sus producciones y reciben retroalimentación (p. 95) por parte de una comunidad más extendida.

Howard Rheingold (2012), define la alfabetización mediática como la capacidad de manejar los aspectos técnicos de las redes y plataformas, pero también como la habilidad para comprender y cumplir las normas básicas de convivencia en las comunidades digitales en términos de cómo crear información y ponerla en circulación. En la misma línea, danah boyd (2016) señala que la alfabetización mediática en la era de las redes ya no está solamente relacionada con interpretar imágenes, texto y contenido en general producido por otros: además de entender el contenido e interpretarlo, es necesario analizar "cómo ese contenido llegó allí en primer lugar. [...] la información 
Mariana Ferrarelli

Alfabetismos aumentados: producir, expresarse y colaborar en la cultura digital

es poder. Esto puede ser empoderante pero también puede convertirse en una herramienta de manipulación" (p. 105). Mimi Ito (2016) señala la necesidad de trascender el concepto de "alfabetización mediática", dado que este aún conserva vestigios de una mirada más tradicional sobre los medios, en la cual bastaba con criticar las agendas comerciales e interpretar el contenido elaborado por las grandes corporaciones. Los desarrollos recientes de Jenkins et al. (2020) avanzan en esa dirección a través del concepto de "imaginación cívica", una categoría que define como la capacidad de analizar el panorama económico y sociocultural actual e imaginar alternativas solidarias y colectivas a partir de intereses compartidos.

\section{De la alfabetización mediática al alfabetismo transmedia}

En el contexto participativo de las redes sociales y la web 2.0 (O’Reilly, 2005), enseñarle a los estudiantes a ser agudos analistas de mensajes no es garantía de que serán participantes responsables y coherentes con valores compartidos: "Tal vez el concepto de alfabetización mediática no sea el término correcto. Debemos pasar de preguntarnos ¿Cómo puedo protegerme de las corporaciones mediáticas? para empezar a pensar ¿Cómo puedo contribuir con mis producciones de un modo efectivo y responsable?" (Ito, 2016, p. 108). Aquí es preciso avanzar hacia definiciones más dinámicas de las habilidades que los usuarios precisan para convertirse en participantes activos y comprometidos en el universo de redes y plataformas. Es necesario promover la reflexión sobre sus prácticas y el modo en el que la estructura y el modelo de negocio propio de las plataformas afecta sus decisiones y eventualmente sus deseos y subjetividad.

Finalmente, emergen los últimos desarrollos relacionados con un nuevo tipo de alfabetización denominada "transmedia", cuyo énfasis se concentra en las habilidades productivas y de gestión de la información y la seguridad en la web que se requieren para interactuar con otros, a la vez que producen y comparten contenidos en el mundo virtual. El centro de estos avances está ocupado por el proyecto de investigación que lideró Carlos Scolari (2018) en varios países de Europa y Latinoamérica y que tuvo el objetivo de identificar específicamente las competencias que los jóvenes ponen en juego mientras utilizan tecnología digital en su tiempo extraescolar. Se destacan las habilidades de producción y gestión de la información, las performativas y de participación y las competencias éticas y de prevención de riesgos.

Scolari (2018) se pregunta por la relación entre las condiciones sociotécnicas y la vida social de los jóvenes. Para ello, explora las transformaciones generadas en diversos ámbitos por el nuevo ecosistema mediático y la arquitectura participativa de las redes sociales. Su objetivo es trascender las definiciones clásicas de alfabetización mediática por encontrarlas ligadas a los modelos broadcast de la radio, la televisión y los demás medios tradicionales. Según el autor, si a la alfabetización tradicional le siguió la me- 
Austral Comunicación

Volumen 10, número 2 (Diciembre de 2021): 395-411 ISSN (I) 2313-9129. ISSN (E) 2313-9137

diática, en la actualidad corresponde hablar de alfabetización transmedia. Para ello, define diferencias y similitudes con las concepciones anteriores, que se detallan en el siguiente esquema:

Tabla 1. Comparación entre alfabetismo tradicional, mediático y transmedia

\begin{tabular}{|c|c|c|c|}
\hline & Alfabetismo & Alfabetismo mediático & Alfabetismo transmedia \\
\hline Lenguaje & $\begin{array}{l}\text { Texto escrito } \\
\text { (leer/escribir). }\end{array}$ & Multimodal. & Multimodal. \\
\hline Soporte & $\begin{array}{l}\text { Libros y textos escritos. } \\
\text { Medios impresos. }\end{array}$ & $\begin{array}{l}\text { Medios interactivos, } \\
\text { audiovisuales y digitales. }\end{array}$ & $\begin{array}{l}\text { Transmedia y redes } \\
\text { digitales. }\end{array}$ \\
\hline Objetivos & $\begin{array}{l}\text { Crear lectores críticos y } \\
\text { escritores. }\end{array}$ & $\begin{array}{l}\text { Crear espectadores } \\
\text { críticos y, a veces, } \\
\text { productores. }\end{array}$ & $\begin{array}{l}\text { Crear prosumidores } \\
\text { críticos. }\end{array}$ \\
\hline Interpelación & Como analfabeto. & $\begin{array}{l}\text { Como consumidor } \\
\text { pasivo. }\end{array}$ & Como prosumidor. \\
\hline Dirección & Top-down. & $\begin{array}{l}\text { Top-down. } \\
\text { Bottom-up. }\end{array}$ & $\begin{array}{l}\text { Bottom-up. } \\
\text { Top-down. }\end{array}$ \\
\hline $\begin{array}{l}\text { Lugar de } \\
\text { aprendizaje }\end{array}$ & Formal (escuelas). & $\begin{array}{l}\text { Formal (escuelas), no } \\
\text { formal e informal. }\end{array}$ & De informal a formal. \\
\hline $\begin{array}{l}\text { Rol del } \\
\text { profesor }\end{array}$ & $\begin{array}{l}\text { Autoridad con el } \\
\text { conocimiento. } \\
\text { Mediador entre el } \\
\text { estudiante y el texto. }\end{array}$ & $\begin{array}{l}\text { Mediador de } \\
\text { conocimiento. } \\
\text { Creador de experiencias } \\
\text { de aprendizaje con los } \\
\text { medios. }\end{array}$ & $\begin{array}{l}\text { Facilitador del } \\
\text { conocimiento. } \\
\text { Traductor cultural. }\end{array}$ \\
\hline $\begin{array}{l}\text { Referencias } \\
\text { teóricas }\end{array}$ & Lingüística. & $\begin{array}{l}\text { Teoría de los efectos de } \\
\text { los medios masivos. } \\
\text { Estudios culturales. }\end{array}$ & $\begin{array}{l}\text { Ecología de los medios. } \\
\text { Narrativas transmedia. } \\
\text { Estudios culturales. }\end{array}$ \\
\hline
\end{tabular}

(Fuente: Scolari, 2018).

En un artículo recientemente publicado, Scolari et al. (2019) utilizan el término "alfabetismo transmedia" y lo distinguen de "alfabetización". Si bien ambos provienen del vocablo inglés literacy, por "alfabetismo" se refieren a "un conjunto de competencias transmedia que el sujeto ha aprendido en entornos formales e informales, desde redes sociales, hasta comunidades de videojugadores, YouTube o foros de discusión" (2019, p. 121). En cambio, el proceso de alfabetización es definido como un programa de acción destinado a recuperar esos conocimientos dentro del entorno educativo formal (Scolari, 2018). En este caso, parecen ser los ámbitos en los que se genera y sistematiza 
Mariana Ferrarelli

Alfabetismos aumentados: producir, expresarse y colaborar en la cultura digital

el conocimiento (informal, mayormente en el primer caso, y formal en el segundo) la variable que distingue ambas concepciones.

Si bien la escuela es el ámbito formal por excelencia en el cual debería desarrollarse un programa de alfabetización transmedia, también es posible pensar que el alfabetismo, más informal y fragmentario, se desarrolla no solo fuera, sino también dentro de la escuela: las fronteras se diluyen y los saberes impregnan prácticas tanto dentro como fuera del aula. Para Jenkins (2008), la alfabetización supone necesariamente no solo consumir textos y contenidos, sino también generarlos: "Del mismo modo que tradicionalmente no asumiría que alguien es alfabeto porque sabe leer pero no escribir, tampoco deberíamos asumir que alguien posee alfabetización mediática si puede consumir pero no expresarse en el lenguaje de los medios" (s.p.). Consumo y producción de mensajes y medios aparecen como habilidades entrelazadas y constitutivas la una de la otra.

Buckingham (2005) profundiza en estas diferencias mediante lo que él denomina educación "en" y "con" medios. En el primer caso, el autor se refiere a la alfabetización digital en términos de cómo fue definida en párrafos anteriores, esto es, como un conjunto de habilidades que se busca desarrollar desde la escuela para que los estudiantes sean usuarios críticos y activos de los medios. La educación en medios busca que los jóvenes mismos se conviertan en productores de mensajes y contenidos. Según el autor,

la alfabetización digital no se reduce a la cuestión de proteger a los niños de los peligros de los medios digitales. Como sucediera con los medios más antiguos, los niños necesitan sentirse autorizados para tomar decisiones informadas en nombre propio para autoprotegerse y autorregularse. Y de la misma manera que la alfabetización clásica implica aprender a escribir y a leer, la alfabetización digital ha de implicar la producción creativa en los nuevos medios y a la vez el consumo crítico de los mismos. (Buckingham, 2005, p. 276)

Educar con medios supone utilizar distintas plataformas y dispositivos con sentido pedagógico para dictar diversos contenidos disciplinares. Respecto a este punto, el autor advierte: "El punto decisivo aquí es que ninguno de estos medios puede considerarse sin más en un vehículo neutro al servicio de la 'información"' (Buckingham, 2005, p. 276). Si bien en este segundo caso la prioridad no es desarrollar competencias críticas en los alumnos, consideramos que la integración de tecnología en los diseños didácticos contribuye, aunque sea informalmente, al desarrollo de competencias en los estudiantes. Aunque ello ocurre dentro de la institución escolar, su carácter informal acerca a la educación con medios al concepto de "alfabetismo" tal como lo entienden Scolari et al. (2019): como un abanico de habilidades adquiridas en diferentes ámbitos a partir de la interacción con las tecnologías. 
Austral Comunicación

Volumen 10, número 2 (Diciembre de 2021): 395-411 ISSN (I) 2313-9129. ISSN (E) 2313-9137

\section{Alfabetismos aumentados}

Alineado con los desarrollos teóricos que asocian el currículo con estructuras ideológicas y de control social (Bernstein, 1994; Bourdieu y Passeron, 1977; Giroux y Penna, 1979), Apple (1994) se pregunta por el modo en el que algunos aspectos del quehacer cultural se presentan como conocimiento objetivo y se perciben de forma naturalizada y dada. En el mismo sentido, es preciso que tanto docentes y alumnos como actores de la cultura digital en general expliciten los sentidos de la integración tecnológica y analicen qué concepciones de enseñanza y aprendizaje subyacen al tipo y modo de utilización de diversos dispositivos y aplicaciones.

Cuando un proyecto digital, educativo o no, contempla la utilización de ciertas herramientas digitales que no conforman en sí mismas un programa estructurado de educación en medios, creemos que igualmente posee un efecto alfabetizante más informal alineado con la noción de "alfabetismo". Este alfabetismo funcionaría como currículum oculto en el sentido de contener expectativas y concepciones respecto a lo tecnológico y lo pedagógico que no son normalmente explicitadas y problematizadas. Traer a la superficie esas concepciones que se cristalizan en prácticas concretas y sistematizar su análisis es un paso esencial para la comprensión de las destrezas que emergen en los nuevos escenarios. Comprender los riesgos de las noticias falsas, el diseño adictivo y comercial de las plataformas y el uso cuasi monopólico y opaco de los datos de los usuarios por parte de las corporaciones propietarias de los medios implica poner en tensión las propias prácticas y tener estas variables en cuenta tanto en el uso de las plataformas como en el diseño de diversas propuestas y entornos de trabajo.

El objetivo es interrogar las prácticas de los usuarios a la luz de la asistencia algorítmica, los desarrollos en big data e inteligencia artificial y otros aspectos asociados a la naturaleza corporativa y comercial de las plataformas, para así revisar cómo se construye la socialidad y la subjetividad a partir de la exposición en redes. Pensar los alfabetismos en clave "aumentada" supone concebirlos en dosis heterogéneas de aprendizajes que se van acumulando y modificando mutuamente y acompañan a los sujetos en sus desempeños a lo largo y a lo ancho de la cultura digital. Subyacen a la formación de prosumidores críticos en prácticas y contextos en crisis y recombinación constante de saberes y formatos: nos referimos a los cruces entre la intermitencia online/offline, sincrónico/asincrónico, grupal/individual, dentro/fuera del aula, campo profesional/ educativo, etc.

De modo provisorio, compartimos una caracterización de los alfabetismos aumentados para continuar su análisis:

Transversales: los alfabetismos aumentados se instalan como una red de saberes y enfoques para abordar situaciones áulicas y extraáulicas de manera integrada. Atraviesan todos los dispositivos y prácticas y contribuyen gradualmente al desarrollo 
Mariana Ferrarelli

Alfabetismos aumentados: producir, expresarse y colaborar en la cultura digital

de una identidad y un habitus en los usuarios. De aquí que resulte vital proponer un programa de alfabetización digital desde instancias formativas formales para acompañar y poner en tensión desde el inicio los aprendizajes que los usuarios construyen informalmente en su tiempo de ocio.

Expandidos: se activan de modo "multiplataforma" y se adaptan a contextos variados. Por eso incluyen aprendizajes que conectan la intermitencia y materialidad de los escenarios online/offline, lo sincrónico/diacrónico y el mundo físico con el mundo virtual en clave onlife (Floridi, 2014).

Móviles: lo son en un doble sentido: por un lado, están asociados a la portabilidad y nomadismo de dispositivos y prácticas, por otro, conforman una constelación de saberes y márgenes de acción en permanente construcción y movimiento. Moldean una masa de haceres siempre en expansión y reformulación, un objeto inacabado y vital.

Situados: permiten definir cursos de acción y reflexión que se adaptan a contextos diversos. Trazan trayectorias y opciones variadas para la obtención de los resultados deseados.

Complejos: configuran un entramado poliédrico y divergente que alberga distinciones y miradas sobre los sujetos, las herramientas y las posibilidades de acción que, a la vez, se conecta con otras capas de saber.

Contingentes: aunque acumulativos, poseen un carácter parcial y efímero. El modo de operar que resulta efectivo en un contexto tal vez sea descartado en otra situación.

Más allá de las habilidades específicas en cada caso, lo importante es desarrollar disposiciones para abrazar los desafíos y la incertidumbre de un contexto particular, ya sea educativo, laboral, personal o social. Mantener el deseo de aprender y apoyarse en otros para aumentar el potencial propio y ajeno implica un abordaje diferente de la subjetividad, asociado a la flexibilidad de los escenarios digitales.

\section{Conclusión}

Las capacidades a las que hacemos referencia involucran saberes y posibilidades de acción instrumentales, pero también sensibilidades sociales, didácticas, cívicas, expresivas, lúdicas, en datos e informacionales, entre otras. No se trata de una colección estática de habilidades, sino de un conjunto multiforme y en expansión a partir del cual los sujetos construyen sus desempeños en los escenarios contemporáneos que son expandidos y divergentes. Asimismo, tal como señala Buckingham (2018), no comprenden un conjunto de disposiciones que se adquieren de manera natural o automática, sin esfuerzo y mediante la mera exposición o uso de medios y herramientas. Suponen salir de la zona de confort, tomar riesgos y definir conscientemente un esquema de trabajo que asegure diversas producciones y desempeños. 


\section{Austral@municación \\ Volumen 10, número 2 (Diciembre de 2021): 395-411 ISSN (I) 2313-9129. ISSN (E) 2313-9137}

Pensar los alfabetismos aumentados se relaciona menos con dispositivos y herramientas y más con los formatos y las prácticas que emergen en los escenarios complejos. Las oportunidades expresivas, cívicas y epistemológicas que presentan las plataformas solo pueden ser aprovechadas si se ponen en diálogo con viejos y nuevos aprendizajes en el diseño de propuestas abiertas y genuinas.

Producir contenidos y materiales digitales, expresarse mediante variados lenguajes y plataformas, a la vez que se intercambian ideas y posiciones en diferentes entornos, supone el despliegue de habilidades complejas que se resignifican en cada nueva interacción. Comprender un mensaje mientras se realiza la lectura crítica sobre su origen y los fines de su distribución (culturales, comerciales, sociales, políticos, académicos, etc.) involucra mecanismos reflexivos que van más allá de comprender las pautas del lenguaje verbal o audiovisual. La investigación sobre los alfabetismos aumentados busca conectar los conocimientos que construyen las y los usuarios en sus prácticas tecnológicas cotidianas con instancias formales de reflexión para indagar en la naturaleza múltiple y opaca de la cultura digital.

\section{Referencias}

Apple, M. (1994). Educación y poder. Paidós.

Area Moreira, M. (2012). La alfabetización en la sociedad digital. En Area Moreira, M.; Gutiérrez Martín, A. y Vidal Fernández, F. Alfabetización digital y competencias informacionales (pp. 3-42). Ariel.

Bernstein, B. (1994). La estructura del discurso pedagógico. Clases, códigos y control (Vol. IV). Morata.

Bourdieu, P. (2005). Capital cultural, escuela y espacio social. Siglo XXI.

Bourdieu, P. y Passeron, E. (1977). La reproducción. Elementos para una teoría del sistema de enseñanza. Laia.

boyd, d. (2016). Introduction. En Jenkins, H., boyd, d. e Ito, M., Participatory Culture in a Networked Era: A Conversation on Youth, Learning, Commerce, and Politics (s.p.). Polity Press.

Buckingham, D. (2005). Educación en medios. Alfabetización, aprendizaje y cultura contemporánea. Paidós.

Buckingham, D. (2018). Foreword. En Scolari, C. (Ed.), Teens, media and collaborative culture. Exploiting teens' transmedia skills in the classroom (pp. 5-7). Transliteracy.

Codina, L. (2018a). Revisiones bibliográficas sistematizadas: Procedimientos generales y Framework para Ciencias Humanas y Sociales. Máster Universitario en Comunicación Social, Departamento de Comunicación, Universitat Pompeu Fabra. https://repositori.upf.edu/handle/10230/34497.

Codina, L. (2018b). Revisiones sistematizadas para trabajos académicos 
1: conceptos, fases y bibliografía. https://www.lluiscodina.com/ revisiones-sistematizadas-fundamentos/.

Doueihi, M. (2010). La gran conversión digital. Fondo de Cultura Económica.

Dussel, I. y Quevedo, L. A. (2010). Educación y nuevas tecnologías: los desafíos pedagógicos ante el mundo digital. Santillana. https://www.unsam.edu.ar/escuelas/ humanidades/actividades/latapi/docs/Dussel-Quevedo.pdf.

Ferrarelli, M. (2017). Modos descentrados de autoría en la era de la web participativa y social. Revista Perspectivas Metodológicas, II(20), 63-76. http://revistas.unla.edu.ar/ epistemologia/article/view/1655/1226.

Ferrarelli, M. (2020). Panmedia: diásporas que se abren y paréntesis que se cierran. Sangrre. https://sangrre.com.ar/2020/06/03/ practicas-panmedia-diasporas-que-se-abren-y-parentesis-que-se-cierran/.

Ferrés, J. y Piscitelli, A. (2012). La competencia mediática: propuesta articulada de dimensiones e indicadores. Comunicar, 19(38), 75-82. https://doi.org/10.3916/ C38-2012-02-08.

Floridi, L.(Ed.) (2014). The Onlife Manifesto: Being Human in a Hyperconnected Era. Springer Open. The Onlife Manifesto: Being Human in a Hyperconnected Era.

Giroux, H. y Penna, A. (1979). Social Education in the Classroom: The Dynamics of the Hidden Curriculum. Theory and Research in Social Education, 7(1), 21-42 https:// doi.org/10.1080/00933104.1979.10506048.

Gutiérrez Martín, A. (2003). Alfabetización digital. Algo más que ratones y teclas. Gedisa.

Instituto Iberoamericano de TIC y Educación. (s.f.). Manual para la evaluación de proyectos de inclusión de TIC en educación. OEI.https://oei.org.ar/ibertic/evaluacion/ pdfs/ibertic_manual.pdf.

Instituto Nacional de Tecnologías Educativas y Formación del Profesorado. (2017). Marco Común de Competencia Digital Docente. Ministerio de Educación, Cultura y Deporte. http://blog.educalab.es/intef/2016/12/22/ marco-comun-de-competencia-digital-docente-2017-intef.

International Society for Technology in Education. (2017). ISTE Standards: Educators. https://www.iste.org/standards/iste-standards-for-teachers.

Ito, M. (2016). Learning and Literacy. En Jenkins, H., boyd, d. e Ito, M., Participatory Culture in a Networked Era: A Conversation on Youth, Learning, Commerce, and Politics (s.p.). Polity Press.

Jenkins, H. (2006). Convergence Culture. La cultura de la convergencia en los medios de comunicación. Paidós.

Jenkins, H. (2008). From production to Produsage: An interview with Axel Bruns (Part One).http://henryjenkins.org/2008/05/interview_with_axel_bruns.html.

Jenkins, H. (2016). Participatory Learning. En Jenkins, H., boyd, d.e Ito, M., Participatory 
Austral Comunicación

Volumen 10, número 2 (Diciembre de 2021): 395-411 ISSN (I) 2313-9129. ISSN (E) 2313-9137

Culture in a Networked Era: A Conversation on Youth, Learning, Commerce, and Politics (s.p.). Polity Press.

Jenkins, H., Clinton, K., Purushotma, R., Robison, A. J. y Weigel, M. (2006). Confronting the Challenges of Participatory Culture: Media Education for the $21^{\text {st }}$ Century. Fundación MacArthur. https://www.macfound.org/media/article_pdfs/jenkins_ white_paper.pdf.

Jenkins, H., Peters-Lazaro, G. y Shresthova, S. (2020). Popular Culture and the Civic Imagination. Case Studies of Creative Social Change. New York University Press.

Lara, T. (2009). Alfabetizar en la cultura digital. En Lara, T. y Alonso Arrukero, N. (Coords.), La competencia digital en el área de Lengua (s.p.). Editorial Octaedro. https://tiscar.com/wp-content/uploads/2011/07/ALFABETIZAR_EN_LA_ CULTURA_DIGITAL-TISCAR-LARA-COMPETENCIA_DIGITAL_ LENGUA-2008.pdf.

O'Reilly, T. (2005). What Is Web 2.0? Design Patterns and Business Models for the Next Generation of Software. O'Reilly Media. http://oreilly.com/web2/archive/what-isweb-20.html.

Pedró, F. (2011). Tecnología y escuela: lo que funciona y por qué. Documento básico $26^{\circ}$. Semana monográfica de la educación. La educación en la sociedad digital. Fundación Santillana: https://fundacionsantillana.com/publicaciones/ tecnologia-y-escuela-lo-que-funciona-y-por-que/.

Rheingold, H. (2012). Net Smart: How to thrive online. MIT Press.

Ribeiro Pessoa, M. T., Hernández Serrano, M. J. y Muñoz Rodríguez, J. M. (2015). Aprendizaje informal, alfabetización mediática e inclusión social. Descripción de una experiencia. Profesorado. Revista de currículum y formación del profesorado, 19(2). https://www.ugr.es/ recfpro/rev192ART5.pdf.

Scolari, C. (Ed.) (2018). Teens, media and collaborative culture. Exploiting teens' transmedia skills in the classroom. Transliteracy.

Scolari, C. A., Lugo, N. y Masanet, M. L. (2019). Educación Transmedia. De los contenidos generados por los usuarios a los contenidos generados por los estudiantes. Revista Latina de Comunicación Social, (74), 116-132. http://www. revistalatinacs.org/074paper/1324/07es.html.

Trejo Delarbre, R. (2021). Prólogo. Para indagar y comprender la cultura digital. En Flores-Márquez, D. y González Reyes, R., La imaginación metodológica. Coordenadas, rutas y apuestas para el estudio de la cultura digital (pp. 7-11). Tintable.

UNESCO. (2011). ICT Competency Framework for Teachers. https://en.unesco.org/ themes/ict-education/competency-framework-teachers. 